\title{
The Principle of Subsidiarity
}

\author{
Athinodoros D. Doussis \\ Panteion University, Athens, Greece \\ Vassiliki Delitheou \\ Panteion University, Athens, Greece \\ Constantinos GE. Athanassopoulos \\ Neapolis University Pafos, Paphos, Cyprus
}

\begin{abstract}
The power of the Greek intellect has been evinced in the principle of subsidiarity “... for he ought to have a proper power, and such a one is that which will be sufficient to make the king superior to any one person or even a large part of the community, but inferior to the whole...", Politics by Aristotle, Book 3, $1286 \mathrm{~b}$. The principle of subsidiarity inspires each building of federal type and it should be applied with spirit of collaboration of various rungs of power. The principle of subsidiarity does not constitute a principle of distribution of competences but regulates the exercise of powers and fixes in who sectors is permissible the action of Union establishing a type of evidence in favor the more inferior rung with the thought that, when the decision is taken as much as possible more near interested, in the citizen, it has increased prospects of effectiveness, after it creates to him a feeling of proximity and attendance in this. In accordance with this principle, the Union may intervene in areas which do not fall within its exclusive competence only insofar as the objectives of the intended action cannot be sufficiently achieved by the Member States but can rather, by reason of the scale or effects of the proposed action, be better achieved at Union level. The principle of subsidiarity constitutes driver as for the way at which it should be practiced this powers in European level. It is intended to determine whether the Union can intervene or should let the Member States take action. The subsidiarity constitutes dynamic significance and it must be applied in the light of objectives that are mentioned in the Treaty.
\end{abstract}

Keywords: principle of subsidiarity, Aristotle, democratic deficit in European Union, Treaty of Lisbon

\section{Introduction}

The European Union is founded in Law (Hallstein, 1974). It was created by law, generates law, and is controlled by law. The Union has only the powers that its members have granted and they have been assigned to it. That is why it is not a "state" but a supranational institution with a pre-federal structure, an institution on the road to federal integration based on the agreement of its members (Elazar \& Greilsammer, 1986).

This "agreement" embodied in the Treaty of Rome defines the whole life of the legal order in the Union. Thus, the Treaties are considered a Constitution in which the fundamental aims of integration and its means of realization are proclaimed and stated.

\footnotetext{
Athinodoros D. Doussis, Ph.D. Student, Department of Public Administration, Panteion University, Athens, Greece.

Vassiliki Delitheou, Ph.D., Permanent Assistant Professor, Panteion University, Department of Economics and Regional Development, Athens, Greece.

Constantinos GE. Athanassopoulos, Ph.D., President of the School of Law, Neapolis University Pafos, Cyprus.
} 
The stages of the process towards integration as well as the intensity continue to be determined by the Member States which do not simply define the course of the Community (Dagtoglou, 1985). The intensity and the extent of the loss of national sovereignty is a part of the consolidation stage. For the time being, Member States remain the essential members of the Treaties (Papagiannis, 2011).

The touchstone of this structure is neither buildings in Brussels nor politicians. The touchstone is the European Citizens. Many people wonder whether there is a principle that guarantees decision-making at the lowest level and if it exists, it strengthens the effectiveness and democratic legitimacy of the Union.

\section{Subsidiarity as a Principle of the Exercise of Union Responsibilities}

\section{Historical Review of the Principle of subsidiarity}

The matter of subsidiarity has been a really controversial one among lawyers as the principle of subsidiarity even since the signing of the Treaty of Maastricht from European Union in the Netherlands. The Treaty was signed in Maastricht on 07/02/1992 and it was put into force on 17/11/1993. If the institutional system of the founding Treaties "followed" the federal system of governance in consistency, they should have included a clause similar to that of existing in many federal states, which regulates the distribution of responsibilities between the federation and the Member States (Wheare, 1963).

It could be argued that the principle of subsidiarity is a creature of Greek intelligentsia. At least in an early form, it is formulated in Aristotle's Politics, where he tries to give the content of the science of political phenomena and political practice. It is the center of political analysis, and the character of the third book is more theoretical than the others.

In modern times, this principle was formulated by Pope Pius XI in 1931 in a circular. The circular Qua dragesimo Anno was published on 15 May 1931.

This principle also applies to modern European federal states (Germany, Switzerland, Austria), although it is not explicitly mentioned in their constitutional law. Even in Siberian anarchist communities, subsidiarity has been and is a basic method of resolving issues that concern the community. We can therefore support that the principle of subsidiarity is embraced by hundreds of approaches and theories, trying to identify relations between the individual and society as well as between societies and institutions (Lilin, 2009).

The principle of subsidiarity was first established with the first revision of the founding Treaties of the Community with the Single European Act, which was the precursor of generalizing the principle in Community law. This principle is mainly found in federal states, with a view to resolving the problem of exercise of responsibilities between the federation and the states. The principle of subsidiarity was presented in the first Environmental Action Program 1973-1976 and in the Commission's proposals for the Tindermans report. The Single European Act was signed at the Intergovernmental Conference on 17 and 28/02/1986 and put into force on 01/11/1987.

Article $130 \Pi$ in conjunction with Article $130 \Sigma$ established the principle of subsidiarity in environmental law where when national law provided for better protection of the environment then it had priority and Community law remained inactive.

\section{Conditions of Application of the Principle of Subsidiarity}

The principle of subsidiarity has been generalized and has been a general principle of Community law. The etymology of the word comes from the Latin "subsidiarius" and means aid and military aid (the term 
subsidium was used as a military one by Romans). The Court of First Instance of the European Communities decided that the principle of subsidiarity was not a general principle of law as far as the legality of Community action is concerned. The principle of subsidiarity has established a kind of competition between the Community and the Member States, which it immediately resolved in favor of the Community: It would exercise competence, provided that its action was better than that of the Member States (Christodoulides \& Stephanou, 1993).

D The application of the principle of subsidiarity is subject to three conditions, which must be cumulative.

$>$ The planned action by the Community should not go beyond exclusive competence.

$>$ The objectives of the proposed action cannot be sufficiently achieved by the Member States.

In view of the scale or effects of the proposed action, it should be achieved at a Community level.

Therefore, the first condition is of a formal nature. In other words, it will first be investigated if the nature of the action envisaged falls within the exclusive competence of the Community. In order to be able to take action at Community level, another condition is required. There must be a thorough investigation into the necessity of the action envisaged, a prerequisite of a substantive nature. Although this estimation is positive, then efficiency, which is a prerequisite of a substantive nature, should also be considered.

When all three conditions are met then only the Community can act.

It should be stressed that if EU competence is established then the action of the Community institutions must not go beyond what is necessary and the content and form of the action must correspond to the objective pursued and use of the milder instrument, principle of proportionality.

The principle of subsidiarity is subject to the jurisdiction of the ECJ, which means that if a Member State doubts or disagrees, it can appeal to the ECJ. Judicial control of such a vague concept is very difficult. The only thing that will be able to judge is whether it is a shared competence. Sufficiency and inadequacy are vague concepts and are purely political judgments (Staggou \& Saxpekidou, 2000). This in practice means that the institution that has the initiative of adopting an act—-the Commission with legislative initiative-will check whether it is a shared competence and will then state a statement of reasons explicitly referring to the principle of subsidiarity, without mentioning this principle, on the grounds that this objective can be better achieved by Community action.

\section{Specificity of the Conditions With the Revision of the Treaties}

However, contradictory interpretations and approaches to content have remained (Ioakimmidis, 1998), and in order to properly address the problem, a protocol on the application of the principles of subsidiarity and proportionality annexed to the Treaty of Amsterdam was drawn up. Subsidiarity-related regulations remained intact in the Treaty of Nice. The Article 3B $\S 3$ has just been numbered in a different way in the Treaty of Amsterdam as Article $5 \$ 3$. The same numbering remained in the Treaty of Nice.

The following guidelines should be used:

The issue under consideration has transnational aspects which cannot be satisfactorily regulated by action by the Member States.

Actions by Member States alone or lack of Community action conflict with the requirements of the Treaty (such as the need to remedy distortions of competition or to avoid disguised restrictions on trade or to strengthen economic and social cohesion) otherwise, the interests of the Member States. 
Action at Community level entails clear benefits due to the scale or results of the action compared to action at Member State level.

In addition, the Protocol states that Community action should be as simple as possible, consistent with the satisfactory implementation of the measure and the need for its effective implementation. The Community must legislate when necessary.

In order to strengthen the above rules, the Protocol requires the following from the Commission:

to consult extensively before proposing legislation and publish, where appropriate, consultation papers (green papers) apart from cases of particularly urgent or confidential nature;

to justify any proposal in relation to the principle of subsidiarity;

$>$ to take account of the need for the financial or administrative burden on the Community, national governments, local authorities, economic operators and citizens to be minimal and proportionate to the objective pursued;

to submit an annual report to the European Council, the European Parliament and the Council on its implementation, which should also be forwarded to the Committee of the Regions and to the Economic and Social Committee.

Subsidiarity could be seen as a "double-edged sword" (Dehouse, 1994). Its positive concept allows the Community to act if Community action is necessary. On the contrary, its negative concept protects the prerogatives of the Member States against unfair Community intervention, a concept maintained in the final version of Article 3B, since it cannot be relied on to confer additional powers on the Community. The reason why the definition of subsidiarity is so unclear in the Treaty of Maastricht is the fact that there has been little political agreement on the substance of the concept in the European Community (Ioakimmidis, 1995).

If the Community institutional system consistently followed the federal system of government, then the provision laying down the principle of delegated powers would have to be supplemented by another clause similar to that existing in many constitutions of federal states and regulating, way, the division of responsibilities between the federation and the federal states.

The above-mentioned problems were covered by the Treaty of Lisbon, which was ratified by the 27 Member States and has been in force since 1 December 2009. The decision of IGC in 2007 was concerned to the enhancement of the effectiveness and democratic legitimacy of the Union and the coherence of its external action. It follows broadly the provisions of the Treaty establishing a Constitution for Europe and is governed by the principle of competence.

However, the principle of subsidiarity remains an indefinite concept, and the inconsistency persists, but it makes a subdued wording and provides a step for the local and regional authorities of the Member States. So the Union should retreat when sub-national levels are able to carry out the action.

\section{The Democratic Deficit and the Principle of Subsidiarity}

\section{Definition of Democratic Deficit}

The term "democratic deficit" in European institutions implies the exclusion of European citizens from the EU decision-making process. This is a concept that seeks to demonstrate that the EU and its institutions are deprived of democracy because of their complex functioning.

The Union as a supranational organization does not provide the "essential" notion of democracy as it operates at an inter-state level. 
Although since 1979 the direct election of the Members of the European Parliament and the recognition of participation in decision-making were established, there is still an increasing volume of academic books and articles on the democratic deficit. This is a concrete demonstration of the challenge of the Union's democracy. The democratic deficit consists of five elements:

Firstly, European integration has contributed to increasing the executive power and reducing the role of national parliaments.

Second, many analysts conclude that the European Parliament needs further empowerment.

$>$ Thirdly, the elections at European level are not being treated by citizens and politicians with equal importance, so we cannot talk about "real" European elections.

$>$ Fourth, citizens are unable, even in the case of strengthening the EC, to identify themselves with the EU and its institutions, characterizing themselves as "European citizens".

Lastly, the policies pursued by the Union do not always - or almost always - enjoy the widespread approval of citizens, since they are taken centrally away from direct control at national level.

\section{Subsidiarity Principle Reduces the Democratic Deficit (?)}

The need for more effective action, the need for transparency and simplification of the functioning of the Union as well as the enlargement of the powers of the European Parliament and hence the reduction of the "democratic deficit" had already become visible as the current Nice institutional framework could not respond to the Europe of 28 (Papagiannis, 2011). Besides, the Nice arrangements have only been provisional, as is clear from the Treaty itself. The Treaty of Nice incorporates a statement on the future of Europe where there is a need to resolve the above problems where, following a report to be prepared for the Goteborg European Council at its meeting in Laeken/Brussels in December 2001 will adopt a Declaration containing appropriative initiative to continue this process. This process should cover the following issues: (a) how to achieve and maintain a more precise delimitation of competences between the European Union and the Member States in line with the principle of subsidiarity, (b) the Charter of Fundamental Rights of the European Union proclaimed in Nice in accordance with the conclusions of the Cologne European Council, (c) the simplification of the Treaties in order to make them clearer and more comprehensible, and (d) the role of national parliaments in the European construction.

The need to ensure compliance with the principle of subsidiarity has led to the amendment of the Protocol by the creation of new control mechanisms. An important novelty is the provision of Article 5 (3) of the EU Treaty, which states that "National Parliaments shall ensure that the principle of subsidiarity is respected".

Under the new Protocol on the application of the principles of subsidiarity and proportionality, each institution is responsible for ensuring compliance with these principles (Article 1 of the Protocol). Before any proposal for a legislative act, the Commission must conduct extensive consultations on the "regional and local" dimension. Consequently, sub-national units receive for the first time a right of consultation vis-à-vis the Commission, the non-observance of which constitutes essentially procedural relief, which leads to the annulment of the legal act.

The relevant Protocol establishes the effective participation of national parliaments and provides the possibility of bringing them before the Court of Justice which has jurisdiction to hear appeals for infringement of a principle of subsidiarity by a legislative act in accordance with the procedures laid down in Article 263 TFEU, by a Member State or transmitted by a Member State in accordance with its domestic legal order on 
behalf of its national parliament or a body of that parliament. Such appeals may also be exercised by the Committee of the Regions in respect of legislative acts for the adoption of which the Treaty on the Functioning of the European Union provides consultation with the Committee of the Regions.

Finally, the combined reading of the provisions of the Treaty and the Protocol implies the following (Papagiannis, 2011; Chrysomallis, 2010):

> The Union, compared to any other organization, certainly has a surplus of democracy. If a state is chosen as a benchmark, then a deficit is actually found, but it is also found in each state.

$>$ The provisions are essentially based on the provisions of the Treaty of Maastricht, while the Subsidiarity Protocol takes on more tangible and specific content on the procedure to be followed. Its main innovation is, of course, the compulsory interference of national parliaments before adopting the promised legislative act, which are called upon to decide if the principle of subsidiarity is respected.

$>$ There is an explicit reference to the regional and local dimension of the principle of subsidiarity.

All European Institutions have to send them the draft legislative act and any amended drafts, thereby limiting the involvement of national parliaments only in the ordinary legislative procedure by excluding them from the procedure for implementing the legislative measures by the Commission or the autonomous regulatory power of the Council.

The involvement of national parliaments remains advisory because it cannot block the legislative process because the European legislator may after the review decide to maintain, amend, or withdraw the proposal. A genuine veto right is not recognized, but a kind of brake to be re-examined.

The national parliaments first make use of the political bodies of the Union, which means the Commission and the legislative authority (the Parliament, the Council) and then the Court of Justice, with the result that the principle of subsidiarity is first judged politically by placing it in its natural environment.

The possibility of legal appeal is also a matter of importance. Any Member State or any national parliament may bring an action for annulment of the legislative act for breach of the principle of subsidiarity to be transposed by a Member State in accordance with its domestic legal system (Article 8 (a) of the Protocol). The Committee of the Regions may also bring appeals (Article 8 (b) of the Protocol), a major institutional development.

\section{Conclusions}

The principle of subsidiarity is a guide to the way in which competences should be exercised at Union level. This principle solves the problem of the exercise of competences if the Union or the Member States are to legislate rather than the problem of the allocation of responsibilities. Subsidiarity is a dynamic concept and should be applied in the light of the objectives set out in the Treaty.

It is not a principle of allocation of competences but defines the areas in which Union action is permissible and establishes a kind of presumption in favor of the inferior level on the grounds that, when the decision is taken as closely as possible to the citizen, it has increased efficiency prospects, since it creates a sense of proximity and participation in it. Its contribution is also reflected in the obligation for a full and detailed statement of reasons for action at Union level.

Reducing the democratic deficit without overburdening EU activity requires comprehensive information to the national parliaments and at the same time showing particular interest in European affairs.

In the Treaty of Lisbon we can observe the change of legal framework and political architecture. 
The scrutiny of the possibility of legislative action envisaged within the Union is placed within its natural environment, that of political control. Considering the inevitable amalgamation of national and European competences, the involvement of national parliaments at this level in the European legislative process is a positive development, even if it is true to date that they do not show a lot of interest in European affairs. (2010)

The mechanisms devised in the new Treaty essentially create a three-party system but without creating a real third legislature. National parliaments will be integrated into the European legislative process without being an EU institution. Consequently, they will bypass the Council of Ministers.

In summary, we conclude that the institutional balance is changing and there are institutional consequences, primarily for the Commission, which assumes a crucial role - in particular on the basis of the protocol-but the great institutional consequence is the involvement of national parliaments, whose involvement creates critical questions. Their engagement is good on the one hand because obviously democracy is boosted, but on the other hand there is another procedural lingering that will put an end to efficiency. However, there are doubts as to whether parliaments are capable of enhancing the principle of subsidiarity (Bermann, 2008).

The European Union has no shortage of rights and values. From a closer reading of the Treaties we will observe that everything is covered either in the form of values or in the form of objectives.

In other words, we have the goals and values but we do not have the political actions and the financial means to promote our goals and values. Their absence is due to the correlation of political forces in the drafting of the treaties.

Is it time for us to lead a federal-logic and not federal-character political union where independent institutions dominate?

\section{References}

Adonis, A., \& Jones, S. (1991). Subsidiarity and the European community's constitutional future. Discussion Paper No. 2. Oxford: Center for European Studies eds., p.23.

Aliberti, P. (2009). Political control of the implementation of subsidiarity principle. Working Paper, Athens. ENEES eds., p. 6-7, $16-17$.

Barnett, H. (2004). Constitutional and administrative law (5th ed.). London: Routledge-Cavendish, p. 246.

Bermann, G. (2008). National parliaments and subsidiarity: An outsider's view. European Constitutional Law Review, 4(3), pp. 453-459.

Christodoulides, Th., \& Stefanou, K. (1993). The Maastricht treaty. Synthetic View, I. Athens: Sideris eds. p. 89.

Christianos, V. (2011). Introduction to European Union law. Athens: Nomiki Vivliothiki eds., p. 53-58, 89-8.

Christianos, V., \& Perakis, M. (2010). European Union legislation, after Lisbon Treaty. Athens: Nomiki Vivliothiki eds., p. 307-312.

Chrisomallis, M. (2010). Lisbon treaty. Athens: Vas. N. Katsaros eds., p.80.

Cooper, I. (2005). Subsidiarity to the rescue: Why the "early warning system" should be salvaged from the constitutional treaty. Intereconomics, 40(4), pp. 185-190.

Craig, P., \&. De Búrca, G. (2007). EU law: Text, cases, and materials (4th ed.). Oxford: Oxford University Press, p. 155.

Dagtoglou, P. (1985). European Community Law (pp 325 - 328). Athens: Ant. N. Sakkoulas eds., p.80.

Dehousse, R. (1994). Europe after Maastricht: An ever closer union? München: Laws Books in Europe, p. 109-110.

Elazar, D. J., \& Greilsammer, I. (1986). Federal Democracy: The USA and Europe Compared - A political science perspective. Integration through Law, vol.1, book 1, pp. 71-93.

Erdkamp, P. (Ed.). (2007). A companion to the Roman army. Malden, MA: Blackwell Publishing, pp. 224-229.

Hallstein,W (1974). Europe in the making, London, Allen and Unwin eds., pp. 4-95

Ioakimides, P. K. (1995). The revision of the Maastricht treaty. Athens: Themelio eds., p.p. 15, 87-91.

Ioakimides, P. K. (1998). Amsterdam treaty. Athens: Themelio eds., p. 148. 
Ioakimides, P. K. (2010). Lisbon treaty, presentation, analysis evaluation (2nd ed.). Athens: Themelio eds., p.92. Kanellopoulos, P. (2003). European Union law. Athens: Ant. N. Sakkoulas eds., p. 273.

Kalavros, G., \& Georgopoulos, Th. (2010). European Union law, institutional law. Athens: Nomiki Bibliothiki eds., p. 101.

Kokmotou, Z. (2008). Local and regional authorities within the framework of European Integration (Thesis, Panteion University, Athens), p. 70.

Lilin, N. (2009). Siberian education: Training young criminals. Athens: Patakis eds., pp. 345-348

Mousis, N. (2011). European Union, law, economy, politics (13th ed.). Athens: Papazisis eds., p. 125.

Papagiannis, D. (1999). Introduction to European law, Athens-Komotini: Ant. N. Sakkoulas eds., pp. 236-237.

Papagiannis, D. (2005). Sub-national level in European integration. Athens-Komotini: Ant. N. Sakkoulas eds, pp. 81, 125.

Papagiannis, D. (2010). European law (4th ed.). Athens-Komotini: Ant. N. Sakkoulas eds., pp. 96-100.

Papagiannis, D. (2011). European law (5th ed.). Athens-Komotini: Ant. N. Sakkoulas eds., pp. 11, 32, 88, 97-98, 233.

Papagrigoriou, Vl. (2000). The wetlands of international interest. The Ramsar International Convention and the Greek Law System. Athens-Thessaloniki: Sakkoulas eds., p. 159.

Pliakos, A. (2006). European Union law I, institutions. Athens: OPA eds., p. 16.

Pliakos, A. (2012). European Union law. Athens: Nomiki Vivliothiki eds., pp 185-192

Sachpekidou, E. (2011). European law. Athens-Thessaloniki: Sakkoulas eds., pp 241-242.

Skandamis, N. (1994). European law and elements of Greek law of adaptation. Athens-Komotini: Ant. N. Sakkoulas eds, p. 301.

Stagou, P., \& Sachpekidou, E. (2000). European communities law (2nd ed.). Athens-Thessaloniki: Sakkoulas eds, p.143.

Stefanopoulos, St. Th. (2004). Greeks institutions. Athens: Livanis eds, pp. 739-760.

Stefanou, K., Tsinisizelis, M., Fatouros, Ar., \& Christodoulides, Th. (Eds.). (2006). Introduction on European studies. Collective Work, V. A., I. Athens: Sideris eds., pp. 27-143.

Toth, A. G. (1992). The principle of subsidiarity in the Maastricht treaty. Common Market Law Review, Issue 6, pp. 1079-1105.

Tzioka-Evaggelou, P. (2007). Aristotle, Politics III, IV. Thessaloniki: Zitros eds., pp 180-198.

Wheare, K. C. (1963). Federal Government, Stanford University. Oxford: Oxford University Press, p. 89. 